\title{
Unbundling cars to daily use and infrequent use vehicles - the potential role of car sharing
}

\author{
Frances Sprei - Diana Ginnebaugh
}

Received: 12 May 2016/Accepted: 19 February 2018 /Published online: 9 March 2018

(C) The Author(s) 2018. This article is an open access publication

\begin{abstract}
Car sharing is seen as an alternative to car ownership; however, for many households, this option may be unthinkable. In this study, we explore the idea of combining car sharing and vehicle ownership in order to change car purchase behavior to improve the environmental performance of the fleet. We consider the personal vehicle as a bundle of attributes. We look at the distinction between "daily use" and "infrequent use" attributes. "Infrequent use" features are those that are only needed occasionally, e.g., a larger trunk, all-wheel drive, seating for 7 , and long vehicle range. If the vehicle attributes could be unbundled, the personal vehicle would include only those features needed on a daily basis, with car sharing providing the "infrequent use" features. We qualitatively explore what the carsharing service would need to look like to cover the "infrequent use" needs and analyze if the existing services can provide these needs. We base our analysis on literature and interviews with experts and representatives from car sharing and rental car companies in California and Sweden. We find that car sharing today does not cover the needs for unbundling the vehicle. There are not enough "infrequent use" vehicles
\end{abstract}

F. Sprei $(\bowtie)$

Physical Resource Theory, Chalmers University of Technology, 41296 Gothenburg, Sweden

e-mail: fsprei@chalmers.se

D. Ginnebaugh

Precourt Energy Efficiency Center, Stanford University, 473 Via Ortega, Stanford, CA 94305, USA

e-mail: moongdes@stanford.edu available in these services. However, new business models and the growth of peer-to-peer car sharing are already begun to widen the vehicle models available.

Keywords Car sharing · Vehicles · Consumer welfare

\section{Introduction}

Consumers often purchase vehicles that meet or exceed all of their needs - from the daily, commute needs to the rare peak needs. A vehicle that meets all usage cases likely has higher operating costs (higher fuel usage) and capital costs (larger vehicle, more features) than a vehicle that would meet only the daily usage cases, because it has features that are only needed occasionally — such as additional seating, range, cargo, and all-wheel drive. The extra fuel usage and expenses are a burden on consumers. The extra energy usage is detrimental for society through additional air pollution, climate change, and energy security impacts. However, consider a business model where consumers would purchase a vehicle to meet their average (daily) needs instead of their occasional (infrequent) needs, with the option to borrow a variety of vehicles for infrequent use times. This could be a welfare enhancing for the consumer (lower costs, access to a variety of vehicles/features) and for society (reduced externalities). For the car-sharing operators, this may imply a broader market. So far, car sharing has mainly been attractive for consumers that are not dependent on cars on a daily basis. This perspective would allow them to broaden their customer base. For 
auto manufacturers, the benefits might be less obvious, though sales of smaller vehicles might make it easier to meet more stringent environmental regulations. Consumers would only consider this option if their welfare stays the same or is increased with this option.

Consider the vehicle as a bundle of functional attributes (such as safety, seating, luggage space, performance, all-wheel drive (AWD), towing, roof rack) and symbolic attributes (such as vehicle brand, new technology, environmental friendliness). If the vehicle attributes could be unbundled into the features needed for daily use and the features needed for infrequent use, the consumer could choose to only invest capital in the "daily use" features and pay as needed for the "infrequent use" features, as shown in Fig. 1. "Daily use" activities are the ones the consumer engages in most days - e.g., commuting, transporting children to school, and grocery/small item shopping. "Infrequent use" activities only occur occasionally and might include vacations to the mountains or snow, transporting large items, towing a boat or camper, and hosting visitors. The vehicle attributes, either functional or symbolic, that are essential to the consumer are present in both the consumer-owned "daily use" vehicle and the shared "infrequent use" vehicle, while features that are not essential to "daily use" activities are present only in the "infrequent use" vehicle. In Fig. 1, the (-) means this feature is decreased while $(=)$ or $(+)$ means the feature stays the same or is increased. Vehicle price, luggage space, and engine size are likely to decrease from the bundled vehicle to the "daily use" vehicle, while the number of seats could decrease or stay the same (for example, if five seaters are needed daily). Safety and symbolic values would remain the same or increase to avoid decreasing consumer welfare. With shared "infrequent use" vehicles, consumers could see an increase in available features with the variety of models available to borrow.

A key component to the success of this type of business model is to keep the service convenient. It is difficult to compete with the convenience of owning a vehicle and having it available all the time - so the total cost savings would have to be large enough to balance out the inconvenience of borrowing a vehicle. The business model would need to consider the convenience of getting the borrowed vehicle, the availability of particular vehicles on short notice, and the reliability and cleanliness of the vehicles. Additional perks may be necessary to offset the inconvenience, such as a large variety of "infrequent use" features available on the shared vehicles and access to luxury or sports vehicles that many consumers would not have the capital to purchase.

One method of unbundling the vehicle features would be to offer a car-sharing service when purchasing small, fuel-efficient vehicles. We will next explore what that car-sharing service would need to look like for the savings of the service and "daily use" vehicle to outweigh the capital investment and operating costs of a bundled vehicle for the consumer, and whether such a service exists today. The aim of the study is to develop a framework that analyzes the consumer welfare implications based on a literature review and interviews with experts within the car-sharing space. The study focuses on the readiness of the car-sharing operators rather than the user perspective. Testing on consumers is the next step in investigating this framework and should be the focus of future research, but is outside the scope of this paper.

\section{Literature review}

The car as a bundle

In this paper, we conceptualize the car as a bundle of attributes and services. It is thus warranted to look at what may be included in this bundle. The answer will depend on what perspective is taken and what literature is reviewed.

Traditionally, car-choice studies have mainly included attributes of technical-economic character such as vehicle price, size, number of seats, luggage space, engine size, and horsepower (see Choo and Mokhtarian (2004) for a review of car-choice models). Recently, car-choice studies have started to incorporate other aspects as well — mainly behavioral and attitudinal aspects of the purchasing household; some of these attributes imply that the car has some other values than purely functional. Typically, the attitudes to new technology are included when studying the uptake of alternative fuel vehicles, including hybrids and electric vehicles (Bolduc et al. 2008; Eppstein et al. 2011; Ewing and Sarigöllü 2000; Hidrue et al. 2011). There is thus an implication that new technology can have a value for the consumer that is separated from the pure functional value of the car. Environmental attitudes are also 


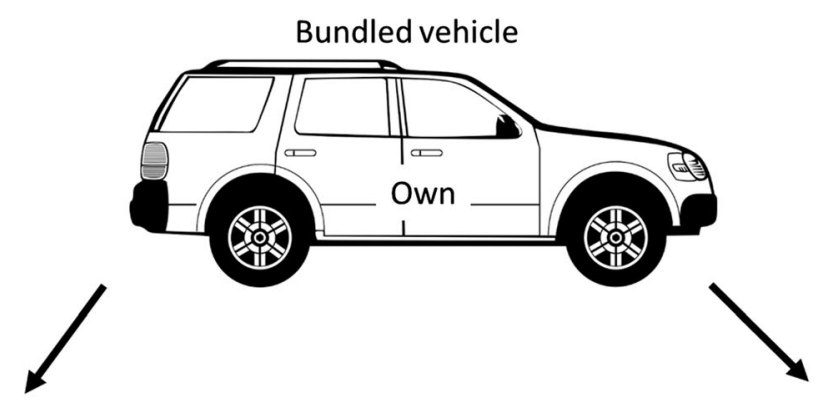

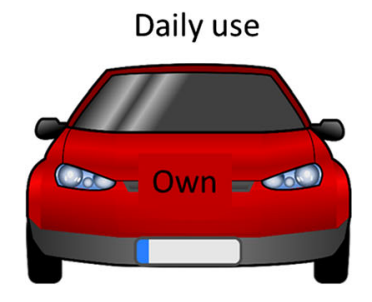

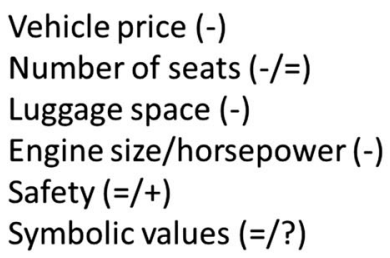

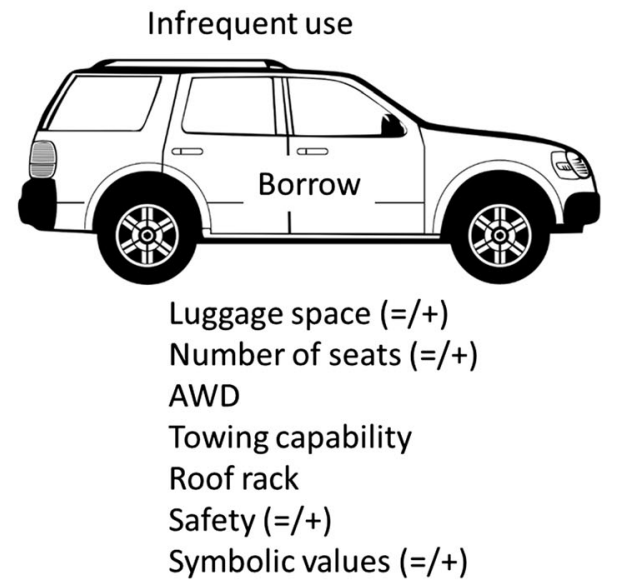

Fig. 1 The bundled vehicle splits into a consumer-owned daily use vehicle and a shared infrequent use vehicle

included in some of the car-choice models (Ewing and Sarigöllü 2000; Hidrue et al. 2011).

Most traditional car-choice models do not take into consideration how the vehicles are used. However, in studies that look at the uptake of electric vehicles, the range of the vehicle and driving habits enter the models directly or indirectly (Mau et al. 2008; Sullivan et al. 2009). The usage can enter these models indirectly through attributes like express or High Occupancy Vehicle (HOV) lane access (Horne et al. 2005), implying that the usage of the vehicle for commuting may have importance for the purchasing decision. Another approach is the cost and time for commuting (Ewing and Sarigöllü 2000).

Driving patterns and car usage have come to the attention of studies that are trying to evaluate how to dimension electric vehicles (EVs) and plug-in hybrid electric vehicles (PHEVs) (Gonder et al. 2007; Pearre et al. 2011). In these studies, the driving pattern and the range of the EVs are the main focus and driving point for assessing the feasibility of the vehicle. Bjornsson and Karlsson (2015) also look at the economic aspects of the vehicles. These types of studies are very useful to determine how one can unbundle the vehicle purely on a usage base: by identifying the usage pattern, the average use can easily be identified as well as the infrequent need for which a car-sharing service might be needed. However, they might miss other dimensions such as the size of the vehicles (occupancy and purpose are not tracked) as well as the more symbolic value of car ownership.

Following the ideas of Dittmar (1992) on material possessions, cars can be seen as having both an instrumental and symbolic meaning. The instrumental is mainly concerning the functional uses of the possession. In the case of the car, it is a means of transportation that can take you and your things from A to B, but even the use-related features can have symbolic elements since they make certain activities possible, such as visiting friends and family and going on leisure trips (Bergstad et al. 2010). The symbolic meaning is connected to the owner expressing who he or she is. From an economic point of view, a car can symbolize wealth and status. Vehicles are a prime example of a positional good and thus conspicuous consumption (Veblen 1899). This is a limiting way of looking at the symbolic value of the car since it only captures one aspect-that the car can communicate wealth (and possibly status) 
(Heffner et al. 2006). The type of vehicle owned can signal identity, beliefs, and values as well (Heffner et al. 2006). The symbolic value of a car is not only a part of an expression of the self but also plays a role in the consumer's social position or membership in a group (Dittmar 1992). To be able to show off the symbolic value, there must be awareness from others on the symbolic values. New technology in new vehicles can embody new meanings that have not existed earlier as Heffner et al. (2007) find among the early adopters of hybrid vehicles in California. In this case, more than communicating an environmental awareness, the ownership of a hybrid vehicle also showed off intelligence and moral considerations for other people (Heffner et al. 2007).

Car manufactures are aware of this and at times strive to take it even one step further when their brand or product becomes a signifier, i.e., when the product itself can communicate certain concepts without needing any assistance from other sources. Volvo and its connection to safety is a prime example (Heffner et al. 2006).

When studying car use motivations, Steg (2005) refers to the emotions related to driving a car along with instrumental and symbolic motives, and how these emotions can influence travel choices. Sprei and Wickelgren (2011) also find an emotional argument beside instrumental and economic factors behind vehicle choice.

The functional/instrumental and symbolic meanings are of course not separated and can interact with each other. Fuel economy for example is a more functional aspect and might influence vehicle choice from a pure economical point of view, but may also have symbolic value such as environmental awareness and concern or in the case of the US even patriotism (Heffner et al. 2007). The role of symbolic value is highlighted in studies of EVs and the early adopters of these (Noppers et al. 2014; Schuitema et al. 2013; Skippon and Garwood 2011).

From the literature review, we can conclude that if we consider the vehicle as a bundle, this bundle includes functional as well as symbolic aspects. None of the literature addresses how these would be affected by unbundling the vehicle attributes based on daily and infrequent usage as is done in this study. One question is how interwoven are these functions? One of the conclusions that we draw is that the daily use vehicle should to as large extent as possible keep the symbolic value of the bundled vehicle. For example, if the bundled vehicle was a high status vehicle, this should be exchanged with a smaller, more fuel-efficient luxury vehicle. The younger generation, for whom smartphones and constant connection is more important, may place less emphasis on the status attributes associated with car ownership (Delbosc and Currie 2013; Kuhnimhof et al. 2012). Another example is EVs which, even when small, have the possibility to carry a high symbolic value (new technology, higher prices, environmental concern) (Noppers et al. 2014; Schuitema et al. 2013; Skippon and Garwood 2011).

The car-sharing space

Car sharing is a relatively new mobility option, which began to gain popularity in the early 2000s in North America (E. Martin et al. 2010) and slightly earlier in Europe (Jorge and Correia 2013). There are several different models of car sharing available today: "traditional" or A-to-A; "one-way," "free-floating," or A-to-B; and peerto-peer or personal vehicle sharing (note on-demand services or transportation network companies (TNCs), such as Uber, are not considered car sharing in the literature). ${ }^{1}$ There are also different business models, for example for profit and non-profit companies, or all EV fleets. Cars are usually rented for short periods of time-minutes to hours - but can be rented for days or weeks, especially in the case of peer-to-peer rentals. Reservations can be made a short time before using the vehicle, and access to the vehicle is often provided remotely, using a special card, key fob, or through a smartphone app.

The traditional car-sharing model provides members with access to a fleet of vehicles which have designated parking spots. The member can reserve the vehicle a short time before using it, use it for hours to days, and then return the vehicle to its parking spot. As of January 2014, there were approximately 1.23 million car-sharing members (traditional and one-way) with access to over 17,000 vehicles in the USA (Le Vine et al. 2014; Susan Shaheen and Cohen 2013; Susan Shaheen and Cohen 2014). Based on surveys in 2005 and 2008, research in the USA has found that overall traditional car sharing reduces or delays car ownership, removes 9-13 cars from the road with each car-sharing vehicle, increases

\footnotetext{
${ }^{1}$ TNCs and on-demand services have the potential to have a large impact on car ownership; however, they will not replace the "infrequent-usage," and thus we have decided to exclude them in this study.
} 
fuel economy of vehicles driven, reduces greenhouse gas emissions, reduces vehicle miles traveled (VMT), and reduces public transit use while increasing walking, biking, and carpooling (Cervero et al. 2007; Martin et al. 2010; Martin and Shaheen 2011a; Martin and Shaheen $2011 b, c)$. The number of cars removed from the road may be lower when looking at a larger share of the population and taking into consideration self-selection bias in the analysis (Clewlow 2016). Mishra et al. (2015) take into consideration the bias and still find significant lower vehicle ownership, but the magnitude of the effect is smaller. Also, car-free households tend to increase VMT and decrease public transit use while members with an existing household vehicle exhibit the opposite behavior (Martin and Shaheen 2011c).

One-way car sharing, also called A-to-B or freefloating, allows the user to pick up the vehicle in one location and drop it off in another after the reservation has concluded. Often, the vehicles can be dropped off either on the street (sometimes with special street parking permits) or at designated parking lots. The energy and VMT impact of this mode of car sharing is not clear - it may be supporting a car-free lifestyle and reducing VMT by monetizing trips directly_ or it may be providing an easy mobility option to use instead of walking/biking/public transportation. Very little peerreviewed research has been done on one-way car sharing. Seattle and San Diego have pilot programs underway to study one-way car sharing (SDOT 2014; Services 2011). In the first phase of the Seattle program, 3 to $4 \%$ of members reported shedding a car after joining the free-floating car-sharing program (7001100 vehicles) (SDOT 2014). However, VMT may have increased, since $63 \%$ of respondents said they did not change personal vehicle usage after joining one-way car sharing (SDOT 2014). This is a concern in other cities, like San Francisco, which excluded one-way car-sharing models from their on-street parking pilot due to limited research demonstrating their environmental and congestion impacts (SFMTA 2013).

Peer-to-peer car-sharing organizations allow members to loan or rent their own personal vehicles to other drivers. It allows privately owned vehicles to increase their utilization and is more able to penetrate areas with lower population density (Ballús-Armet et al. 2014; Hampshire and Gaites 2011; Shaheen et al. 2012). Hampshire and Gaites (2011) found peer-to-peer car sharing to be economically viable, but challenged by public policy, trust, and car insurance. Optimizing reservations can also increase revenue, making the peer-to-peer system more viable (Sinha 2011). This type of car sharing may be the best suited existing model to provide the "infrequent use" vehicle for several reasons: individuals own the vehicles, making low utilization less of a concern; there is no sunk capital cost on the fleet by a company, so the fleet can theoretically grow enough to handle high demand on weekends and holidays without worrying about low use during the work day; and the vehicles could be located right in members' own neighborhoods, providing a low transaction cost for acquiring the vehicle. As quoted by the founder of RelayRides (now Turo), a family could purchase a smaller, more fuel-efficient vehicle that meets their daily needs because they have convenient access to SUVs when one is needed (Abdel-Razzaq 2011). The energy and environment impact of the peer-to-peer model is uncertain. It can increase the utilization of existing vehicles, perhaps reducing or delaying vehicle purchases, which has a positive impact on the environment. It may also increase consumer welfare by providing access to shared vehicles in more locations. However, these vehicles may be older and less efficient than traditional carsharing vehicles. Also, it is unclear whether individuals would purchase an additional car or hold on to an older car because it can be used to make money in peer-topeer car sharing. More research is needed in this area.

An overview of the traditional car-sharing development in Europe is given in the final report of the EUproject momo car sharing (momo 2010) that covers the market in 14 different countries including the provider structure and the spatial distribution of the services. At the time of the report (2009), car sharing was just emerging in many countries with the exception of Switzerland, where more than $1 \%$ of the population was a member of car sharing. The report also covers a survey with 108 of the 205 car-sharing providers. They find that the customer base is mainly private ( $84 \%$ of the users), the rest being business users. The members are mainly male (with the exception of Mobility in Switzerland with a more equal gender distribution) and between 26 and 49 years old. Compared to the general public, carsharing members own fewer cars and are more likely to own some kind of public transportation pass. Similarly, Prieto et al. (2017) find that being male and aboveaverage educated increase the probability of adopting a car-sharing service. The reported number of displaced personal vehicles varies between 4 and 8 per car-sharing vehicle. Compact cars are dominant in the car-sharing 
fleet, and only $4 \%$ of the providers have vehicles with an environmentally friendly drive system. According to a more recent report (Bert et al. 2016), there were over two million car-sharing users in Europe in 2015 and roughly 31,000 vehicles. Germany is being one of the countries with the strongest growth (Bert et al. 2016).

There are a limited amount of studies of car sharing in Europe. Traditional car sharing has been studied in Austria (Prettenthaler and Steininger 1999), Germany (Glotz-Richter 2012; Loose et al. 2006), Ireland (Rabbitt and Ghosh 2013), and specific cities like Lisbon (Baptista et al. 2014) and Rome (Musso et al. 2012). One-way car sharing has mainly been studied through simulated models (Jorge and Correia 2013), while freefloating car sharing has been studied through user surveys in Ulm, Germany (Firnkorn and Müller 2011, 2012), and other German cities (Kopp et al. 2015).

Studies concerning the Swedish car-sharing market can be found in reports from the Swedish Road Administration (Trafikverket 2012, 2013). The market consists of one large commercial operator (Sunfleet) partially owned by Volvo Cars and a large number of smaller coops (27 of these where surveyed in Trafikverket (2013)). What is specific for Sweden is that the vehicles have a high environmental and safety standard. There is a lack of studies of Swedish car-sharing members. The existing reports rely on a few old studies, mainly from other countries (Trafikverket 2012).

The available literature gives us some insights to car purchase behavior and car sharing today, but only separately-information on this new area of how car sharing influences the type of vehicles purchased is limited. Therefore, we gathered further information through interviews with key actors and experts.

\section{Method}

We first developed a framework for the consumer welfare implications of unbundling the vehicle. The framework, combined with results from expert interviews and a literature review, was used to evaluate if today's carsharing space can support an unbundling of the vehicle.

The literature review had two main focuses. The first one is to analyze to what extent the car can be considered a bundle and what can be included in this bundle. For this part, three different types of studies have been included: car-choice studies and the attributes that they include in the choice models, usage-centered studies that mainly look at travel patterns, and studies that include the meaning and more symbolic values of the car. The second focus has been on the car-sharing space covering various forms of car sharing both in the USA and in Europe. Since this space is relatively new, we included peer-reviewed papers, reports, and other gray literatures.

In order to fill the identified gaps from the literature and to get up-to-date information (the car-sharing space is quickly evolving), interviews with relevant actors were carried out in Sweden and in California, USA. California was chosen due to the presence of the major actors of car sharing as well as smaller providers. It is also where some of the major peer-to-peer car sharing started, providing an opportunity to gain insight on how this innovative sector might grow elsewhere. The challenges in Europe are of slightly different character given other urban structures and fuel prices. While other countries in Europe have come further when it comes to the penetration of car sharing, e.g., Switzerland, Sweden has a high adoption rate of mobile and net-based application and is a car-manufacturing country with a tradition of purchasing larger vehicles (Sprei and Karlsson 2013), making it an interesting study when it comes to changing car-purchasing behavior.

In total, 12 semi-structured expert interviews were carried out: 7 in Sweden, of which one also had experience in Switzerland, and 5 in the USA. Interviewees were chosen to get a sampling of the people working for companies with different types of car sharing: car rental, traditional (vehicles are returned to the same place where they are picked-up), one-way (the vehicle is picked up at one location and dropped off at another), electric vehicle (EV)-only, peer-to-peer (vehicles are rented from other private individuals), for profit and non-profit, and coops (members own the car sharing), both in the USA and Sweden. We also interviewed experts from universities and from city and country agencies. In Sweden, four interviewees were managers and in car-sharing companies, three were experts. In California, the division was three car share actors and two experts (one university researcher and one city government analyst).

The interview structure was based on a number of themes: the customers, the fleet, the influence of car sharing on vehicle purchase choice, how car sharing can be supported, and future mobility. At the end of the interview, the idea of unbundling the vehicle was presented to the interviewee for comments. For a 
summary of the different themes from the interviews, please see Sprei and Ginnebaugh (2015).

The interviews range from $41 \mathrm{~min}$ to an hour and $10 \mathrm{~min}$. All of the Swedish interviews were carried out in person, except one which was carried out by phone: all in Swedish. They took place either in the interviewee's office or at Chalmers University. Three of the US interviews took place in person in a University office, at a café, and in a personal home. The two phone interviews were conducted in a home office.

Interviewees are anonymized through initials with their area of expertise, such as "DG-EVonly" and "SSexpert" in the text.

Each interview was recorded and transcribed. The transcribed interviews were analyzed through recursive abstraction based on the different themes. The first step of abstraction was performed by each author separately, while further steps were done by both authors.

The literature and the interviews complement each other: while the literature is more encompassing, it may lack the actuality due to the fast-moving field, which can be addressed by expert interviews. While the number of interviews may be limited, the field is also relatively small and the interviewees have been carefully selected to capture the different types of car sharing. The consumer and user perspectives were not the aim of this study, focusing instead on the readiness of the carsharing operators.

Back-of-the-envelope calculations were made to estimate carbon dioxide emission and fuel savings of unbundling the vehicle to determine the order of magnitude savings possible. The calculations are based on the following equation:

$S=C^{*} M_{\text {ave }}{ }^{*} N_{\text {repl }}{ }^{*} S h_{\mathrm{km}}{ }^{*}\left(F C_{\mathrm{L}}-F C_{\mathrm{S}}\right)$

where $S$ is the saved carbon dioxide emissions $(\mathrm{kg})$, $C$ is the carbon content of the fuel $\left(\mathrm{kg} \mathrm{CO}_{2} / \mathrm{l}\right), M_{\text {ave }}$ is the average annual driving distance of personal vehicles $(\mathrm{km}), N_{\text {repl }}$ is the number of vehicles replaced, $S h_{\mathrm{km}}$ is the share of kilometers replaced (fraction or percentage), $F C_{\mathrm{L}}$ is the specific fuel consumption $(1 / \mathrm{km})$ of the bundled larger vehicles, and $F C_{\mathrm{S}}$ is the specific fuel consumption of smaller vehicle. For the smaller vehicle, two cases were calculated: one for an average smaller vehicle and one for a hybrid vehicle.

For the US case, data for average vehicle kilometers traveled, the share of urban and rural kilometers, the number and type of on road vehicles, and the fuel consumption were gathered from the Federal Highway Administration, part of the US Department of Transportation. ${ }^{2}$ For the Swedish case, data was collected from Statistics Sweden for both specific fuel consumption and average annual kilometers driven (Statistics Sweden 2015). Calculations are made for both diesel and gasoline vehicles and weighted based on the share of vehicles in the fleet.

We use urban kilometers to approximate daily/ commute kilometers that can be replaced with a smaller vehicle and assume the rural miles will still be driven by a borrowed light-duty truck. In the Swedish case, this corresponds to half of the miles traveled (see e.g., Jakobsson et al. (2016) for a distribution of miles traveled). In the USA, approximately two thirds of the miles driven by long wheel base vehicles (i.e., SUVs and trucks) are urban (USDOT 2015).

A number of vehicles replaced are the authors own estimates based on current levels of car-sharing membership in various countries and a moderate upscaling (momo 2010; Shaheen and Cohen 2014).

\section{Results}

Framework for considering consumer welfare implications

Consumer welfare normally refers to the utility that the individual derives from the consumption of goods and services (Khemani and Shapiro 1993). It will depend on given prices and the individual's income and preferences. Here, we create a framework to see how the consumer welfare may be affected by different factors in order to determine some general prerequisites for consumer welfare to remain equal or higher in the case of an unbundling of the vehicle.

In our framework, consumer welfare effects are the sum of the following: capital or sunk costs, operational costs, and other costs that include symbolic value, transaction costs, and convenience costs. Table 1 summarizes the potential changes in consumer welfare. In order for unbundling the vehicle to work on a broad scale, the items in the "welfare gain" row would have to offset or exceed the "welfare loss" items. Lower vehicle capital costs, reduced fuel usage, and the increase in the variety

\footnotetext{
$\overline{2}$ The data is collected from www.fhwa.dot. gov/policyinfromation/statistics/2013. Visited on 2015-09-08.
} 
Table 1 Framework for considering consumer welfare implications of unbundled vehicle

\begin{tabular}{|c|c|c|c|}
\hline & Capital/sunk costs & Operational costs & Other costs \\
\hline Welfare gain & Lower vehicle purchase costs & Less fuel used & Variety of vehicles \\
\hline Welfare loss & Membership costs & Cost of shared vehicle usage & $\begin{array}{l}\text { Proximity of shared vehicle } \\
\text { Planning, reservation time and ease } \\
\quad \text { (app, key exchange,...) } \\
\text { Availability of vehicles } \\
\text { General inconvenience } \\
\text { Ability to leave key items in vehicle } \\
\quad \text { (i.e., car seats) }\end{array}$ \\
\hline Equal & & & Symbolic value of vehicle \\
\hline Uncertain & & Less driving & \\
\hline
\end{tabular}

of vehicles would have to be equal to or higher than the sum of the membership charges, costs of shared vehicle usage, and the harder-to-quantify potential inconvenience of a shared vehicle, including advanced planning, availability of desired vehicle, proximity of the vehicle to customer's location, and the lack of ability to leave key items in the vehicle-like sunglasses and car seats. Another potential welfare loss is a reduction in driving due to pay-as-you-drive payment scheme instead of sunk cost of owned vehicle. However, since the customer still owns a vehicle in this case, this may not be a large factor. Reduction in driving is also a societal benefit even if it is a loss of consumer welfare.

A key feature for this business model to be broadly successful is the symbolic value of the customer's vehicle. It is necessary to maintain or improve the symbolic value of the owned vehicle in order to maintain or improve consumer welfare (Dittmar 1992; Steg 2005). Symbolic value can be maintained by, for example, keeping the same luxury brand in the owned vehicle or by providing some other symbolic values through new technology such as EVs and hybrids.

From a societal welfare point of view, there are gains in the form of less carbon emissions, less local pollutants, and less fuel use. There might also be distributional effects giving access to new vehicles and a larger range of vehicles to lower income groups (point stressed by JH-expert).

Can today's system support an unbundling of the vehicle?

In this section, based on the interviews and literature, we analyze how the current state of car sharing can support a consumer welfare gain if the vehicle would be unbundled based on the framework developed in "Framework for considering consumer welfare implications."

\section{Possible welfare gain from unbundling the vehicle}

The welfare gain is mainly achieved through the lower cost of the purchased vehicle combined with less money spent on fuel since the purchased vehicle will be more fuel efficient (see, e.g., Koopman (1995) for a calculation of consumer welfare of vehicles). For our calculations, we consider two scenarios-where we replace the bundled vehicle with a smaller more fuel-efficient vehicle (35\% lower fuel consumption in the Swedish case, 27\% lower fuel consumption per vehicle in the US case) and with a hybrid vehicle $(60 \%$ lower fuel consumption in the Swedish case, 66\% lower fuel consumption in the US case-the differences are due to the difference in prevalent vehicles in the two countries). For the hybrid, the purchasing costs may not be that much lower, but the unbundling may make a vehicle with more advanced fuel saving technology profitable. There is thus today a potential for a welfare gain.

In the best case scenario, car sharing can give access to a larger variety of vehicles such as convertibles, sports vehicles, and AWD. This would imply a welfare gain for the consumer. To better understand to what extent this was available today, we surveyed the types of models in different types of car-sharing fleets (Table 2). Although this table does not show the number of vehicles available in each category, it does provide insight to the type of vehicles each company emphasizes. The table provides illustrative 
Table 2 Examples of car-sharing companies in Sweden and USA and number of models of different types of vehicles (2014)

\begin{tabular}{|c|c|c|c|c|c|c|c|c|}
\hline Country & Company & Type of service & $\begin{array}{l}\text { Regular } \\
\text { cars }\end{array}$ & $7+$ seaters & $\begin{array}{l}\text { Transport } \\
\text { vehicles }\end{array}$ & AWD & Total & Source \\
\hline \multirow[t]{2}{*}{ Sweden } & Sunfleet & Traditional & 9 & 1 & 3 & 3 & 16 & www.sunfleet.com \\
\hline & Göteborg Bilkoop & $\begin{array}{l}\text { Traditional } \\
\text { non-profit }\end{array}$ & 6 & 1 & 1 & & 8 & www.goteborgsbilkoop.se \\
\hline \multirow[t]{6}{*}{ USA } & Zipcar & Traditional & 18 & 3 & 7 & 3 & 28 & www.zipcar.com \\
\hline & City Carshare & $\begin{array}{l}\text { Traditional } \\
\text { non-profit }\end{array}$ & 19 & 0 & 4 & 2 & 25 & citycarshare.org ${ }^{\mathrm{a}}$ \\
\hline & ReachNow & One-way & 4 & 0 & 0 & 2 & 6 & reachnow.com \\
\hline & $\begin{array}{r}\text { Turo (formerly } \\
\text { RelayRides) }\end{array}$ & Peer-to-peer & 286 & 23 & 155 & 215 & 464 & Turo.com \\
\hline & car2go & One-way & 3 & 0 & 0 & 0 & 3 & www.car2go.com \\
\hline & $\begin{array}{l}\text { Enterprise } \\
\text { CarShare }\end{array}$ & $\begin{array}{l}\text { Traditional } \\
\text { from car rental }\end{array}$ & 20 & 1 & 1 & 1 & 23 & $\begin{array}{l}\text { www.enterprisecarshare. } \\
\text { com }\end{array}$ \\
\hline
\end{tabular}

Some vehicle models are both transport vehicles and all-wheel drive (AWD) but are not double counted in the total. Also, US numbers are approximate-Zipcar depends on the location, and peer-to-peer Turo and Getaround may change frequently. Enterprise CarShare is for San Francisco. The websites were visited in 2017 (expect Enterprise CarShare and City Carshare visited 03-2016)

${ }^{a}$ City Carshare has since we have collected the data merged with Getaround and is no longer a non-profit. See https://www.getaround. com/press/library/2016/11/10-Getaround-And-City-Car-Share-Join-Forces-Establishing-San-Franciscos-Largest-Sharing-Economy. [Accessed 2017-08-23]

examples of operators within each category and is not a full representation of all operators in the car-sharing space. It is easy to see that the smaller coops do not have that much variation, but even the larger traditional car-sharing firms are mainly dominated by regular five seat vehicles. This is not surprising since most of the demand is in this segment (PA-traditional, PM-coop, NS-Car Rental; Martin et al. 2010). However, this will make it harder for car sharing to cover infrequent use needs. Peer-to-peer companies in the USA have perhaps the best potential to cover infrequent use needs with the largest variety of vehicle attributes available to members (AB-p2p, SS-expert, Abdel-Razzaq (2011)).

The interview results also suggest that the access to a large variety of vehicle models is still a limited option. The majority of the vehicles are regular vehicles of small to medium size since these are most popular and reflect the average need for car sharing, i.e., shorter trips with not much luggage (PA-traditional, PM-coop, NS-Car Rental; Cervero et al. 2007; Kim 2015; Martin and Shaheen 2011a; Shaheen and Cohen 2013). Smaller vehicles with higher fuel economy might also increase the profit of the car-sharing company (Bellos et al. 2017). The exact composition of the fleet of the carsharing companies will depend largely on their business model and their company goals. In both Sweden and
California, the non-profits focus on green vehicles (AD-non-profit, MK-expert, PM-coop), but even commercial car sharing incorporates green vehicles in their fleet such as electric vehicles in Car2go and ReachNow. In Sweden, the main commercial company Sunfleet is owned by Volvo and thus their vehicles dominate. Generally, it can be said that the larger the car-sharing company, the easier it is to have a diversity of models such as Mobility in Switzerland and Zipcar in the USA that include more specific models such as sport and luxury vehicles (MK-expert). The car-sharing space is rapidly changing and there are new actors moving into it, especially OEMs creating their own car sharing such As GM's Maven. This might also allow for a larger variety of vehicle models. Maven, e.g., offers a number of SUVs in their fleet. ${ }^{3}$ BMW's ReachNow has also gone from providing only one type of vehicle to up to six models. Still, none of these are seven seaters or transport vehicles. Interviewee AB-p2p mentions that for peer-to-peer, the luxury vehicles were always in demand. These are vehicles that members likely cannot afford on their own or be able to rent elsewhere. The utility vehicles, with the larger cargo space, were also in high demand (AB-p2p).

\footnotetext{
$\overline{3}$ www.mavendrive.com [accessed 2017-08-11]
} 
Possible welfare loss from unbundling the vehicle

Welfare losses are connected to the pricing structure of the car-sharing service. Most car-sharing companies have a monthly membership fee, and then there is a cost per hour and distance traveled for the vehicles (AD-nonprofit, DG-EVonly, UF-EVonly, PA-traditional; momo 2010; Shaheen and Cohen 2014). This implies that for a car-sharing service, capital costs are decreased and mostly transferred to operational costs. In some cases, this pricing structure can be perceived as a barrier (Sochor et al. 2015), since these operational costs are perceived as quite high and people are not always aware of the total costs of ownership of their vehicles (Sprei and Wickelgren 2011; Turrentine and Kurani 2007). Higher operational costs may lead to less driving (SSexpert). Both the interviews and literature on car sharing refer to the fact that car-sharing members often drive less after a while (Cairns 2011; Cervero et al. 2007; Martin and Shaheen 2011a; momo 2010) (even if the exact cause of this has not been investigated). Decreased driving may have societal benefit in lower emissions, but for the individual, there may be a welfare loss if they perceive that they have to give up activities and trips that they otherwise would have partaken in (Bergstad et al. 2010).

The other costs under welfare loss in Table 1 are key issues in making sure that the unbundling actually is attractive to the consumer. One of these aspects is the proximity to the shared vehicle. According to the interviews, customers often chose a vehicle close to them (with the exception that they might walk further to get a cheaper vehicle) (AD-non-profit, AT-expert, PA-traditional, UJ-EVonly, PM-coop). The relevance of strategically situated parking to help promote car sharing also reflects the relevance of location of vehicles (AD-nonprofit, AT-expert, MK-expert, PA-traditional, UJEVonly, PS-expert). Another related aspect is the availability of vehicles. Interviewee MK-expert takes the example of providing two car-sharing parking places next to each other and how that increases the usage of the vehicles at that specific location due to both the perceived and the actual availability of the vehicles. de Lorimier and El-Geneidy (2013) also find that the number of vehicles at a station increases in both availability and usage. Also, membership in car sharing is related to the density of vehicles (according to MK-expert taking Mobility in Switzerland as an example). PA-traditional, NS-Car Rental, and AD-non-profit point to the fact that car sharing has a lower occupancy level than car rental, since availability of vehicles is a key to keeping members.

Practical issues such as ease of reservation, easy working apps, and ways to access keys are important as well (DG-EVonly). Interviewee AD-p2p says "if it wasn't easy it wouldn't work." For peer-to-peer rental making, the booking and key exchange easy is essential (AD-p2p). Other practical issues, such as being able to leave your personal belongings, such as sunglasses or car seats in the car, have anecdotally been brought up as a possible inconvenience (SB-expert).

The inconveniences of car sharing are reflected in the fact that many social and economic groups are hard recruit for car-sharing membership. While growing, the penetration rate is still low in most countries, except Switzerland (momo 2010; Shaheen and Cohen 2014). The concept is still new and unknown to many people, and if they do not perceive car ownership as troublesome, it is difficult to explain the advantages of car sharing (AD-non-profit, DG-EVonly, PA-traditional, NS-Car Rental). For some consumers, such as retired people, younger working class, and high-income people, vehicle ownership still has a high status factor and car sharing may not be desirable (AT-expert, PA-traditional, NS-Car Rental, JH-expert). Paundra et al. (2017) have suggested that the research on car sharing should look closer at psychological ownership, i.e., feeling of ownership related to objects that consumers do not formally own.

Some interviewees mentioned the fact that people might not be comfortable sharing vehicles with total strangers (AB-p2p). Two interviewees (NS-Car Rental, SS-expert) brought up the idea of having different levels of openness of car-sharing circles or fractional ownership to address this. A first step in that direction is being tried by Audi in Stockholm that provides the key and software needed for sharing your vehicle with four other people of your choice. ${ }^{4}$

Interviewees' view of car-sharing vehicle as infrequent vehicle

When car-sharing practitioners and experts were asked if car sharing can affect car purchase choice, the answer was likely yes - people are more likely to purchase the same type of vehicle they typically use in car sharing

$\overline{{ }^{4} \text { https://www.audiunite.com/se/service/sv_unite.html }}$ 
(AD-non-profit, DG-EVonly, SS-expert, AT-expert). Although the interviewees did not have quantitative evidence of this phenomenon, they all invariably had anecdotal evidence to support this claim. AD-non-profit mentions one customer telling her she bought a Scion because she really liked it when she used it in the carsharing service. There is also evidence from the literature that car-sharing members will be more likely to own an alternatively fueled vehicle (Clewlow 2016).

When the idea of grouping together car sharing with the purchase of a fuel-efficient commuter vehicle was presented to the car-sharing practitioners and experts, the reaction was cautious - they generally agreed it was a great idea in theory, but really hard to implement, and not being done today (AD-non-profit, DG-EVonly, ABp2p). Several interviewees mentioned that if such a service existed, the dealers would be in the ideal position to run such a program (SS-expert, AB-p2p, UJ-EVonly, MK-expert, PA-traditional). The dealers could utilize excess capacity on their lots while supporting the sale of more fuel-efficient vehicles. This type of service is already being tried by some automobile manufacturers, such as BMW offering use of an X3 with the purchase of their all electric $\mathrm{i} 3$ and Nissan for the Nissan Leaf. ${ }^{5}$

Some of the interviewees however did mention without being prompted that there is a chance that car sharing could work as the "infrequent use" vehicle ( $\mathrm{JH}$ expert, PA-traditional, PM-expert, NS-Car Rental). JHexpert even stated a term that summarizes the idea quite well: mobility insurance, i.e., a service that provides you with the mobility needed. None of the interviewees however had any evidence that this was actually happening today. While it might seem like an attractive option, some key issues were seen as problematic. For example, there might be a peak demand for larger vehicles during weekends and vacation periods (AB-p2p, AD-non-profit). Also, for a longer trip, such as a 1-week vacation, car sharing becomes too expensive and the rental car is a better option ( JHexpert, PM-coop, MK-expert).

Theoretical energy and carbon emission implications

To test if this new vehicle ownership/vehicle sharing model can help address energy security, air pollution, and climate change, we do a back-of-the-envelope

\footnotetext{
5 http://www.nissan.co.uk/GB/en/vehicle/electricvehicles/leaf/discover/owner-benefits.html
}

calculation of potential fuel savings and carbon dioxide $\left(\mathrm{CO}_{2}\right)$ emission reductions. First of all, it should be noted that we here only look at the user phase of the vehicle and that there is a small chance that the total number of vehicles could increase if consumers continue to own one vehicle in addition to the shared vehicles. However, the user phase of the vehicle life cycle stands for the main environmental impact (Hawkins et al. 2013; Sullivan et al. 1998) and is thus the focus of our calculations. To put these numbers in perspective, we also calculate the number of vehicles these emissions would represent as "vehicles taken off the road." The answer depends on the extent of the adoption and usage of this system and the type of vehicle the light-duty truck is being replaced with for daily use cases. As shown in Table 3 , for the US case, we consider replacing a small percentage $(0.5 \%)$ of the light-duty truck $(17 \mathrm{mpg}$, $14 \mathrm{l} / 100 \mathrm{~km})$ stock with either an average vehicle (23 mpg, $10 \mathrm{l} / 100 \mathrm{~km}$ ) or a hybrid vehicle $(50 \mathrm{mpg}$, $51 / 100 \mathrm{~km}$ ) for urban miles. We use urban miles to approximate daily/commute miles and assume the rural miles will still be driven by a borrowed lightduty truck (USDOT 2015). Even this small adoption level leads to substantial improvements for energy security and the environment, especially with the hybrid vehicle where gasoline is reduced by 540 million liters per year and $\mathrm{CO}_{2}$ emissions are reduced by 1.3 million metric tons per year. This is equivalent to taking approximately 270,000 average vehicles off the road.

For the Swedish calculations, we consider large vehicles to be those with a curb weight above $1700 \mathrm{~kg}$. Five thousand of these vehicles are presumed to be replaced with an average car or a hybrid for half of the miles as a proxy for commuting or daily use. Given the lower number of vehicles, the annual savings are much smaller. However, it would still correspond to up to 1500 vehicles taken off the road and 1.5 million liters of fuel saved.

\section{Conclusions}

Our conclusion is that car sharing as it works today could not serve as an "infrequent use" vehicle to support the unbundling of the vehicle. The main reason for this is the lack of models in the carsharing fleets that meet the infrequent use vehicle 
Table 3 Theoretical energy and carbon emission impacts for replacing light-duty trucks with more fuel-efficient vehicles for urban/daily use miles

\begin{tabular}{|c|c|c|c|c|c|}
\hline \multirow{4}{*}{ U.S. } & \multirow{4}{*}{$\begin{array}{l}\text { If } 500,000 \text { light duty } \\
\text { trucks }(0.5 \% \text { of the US } \\
\text { light truck vehicle stock) }\end{array}$} & \multirow{4}{*}{$\begin{array}{l}\text { are replaced for urban } \\
\text { miles only (65\% of total } \\
\text { miles - as a proxy for } \\
\text { commuting / daily use) }\end{array}$} & & \multicolumn{2}{|c|}{ Replacement vehicle } \\
\hline & & & Reduction / year & Average Car & Hybrid Car \\
\hline & & & $\begin{array}{c}\text { Gasoline (I) } \\
\text { CO2 (metric tons) }\end{array}$ & $\begin{array}{l}220 \text { million } \\
0.5 \text { million }\end{array}$ & $\begin{array}{l}540 \text { million } \\
1.3 \text { million }\end{array}$ \\
\hline & & & $\begin{array}{c}\begin{array}{c}\text { No. of Vehicles taken } \\
\text { off the road }\end{array} \\
\end{array}$ & & \\
\hline \multirow{3}{*}{ Sweden } & \multirow{3}{*}{$\begin{array}{c}\text { If } 5,000 \text { heavy }(>1,700 \\
\mathrm{kg}) \text { vehicles }\end{array}$} & \multirow{3}{*}{$\begin{array}{l}\text { are replaced for half of } \\
\text { the miles (as a proxy for } \\
\text { commuting / daily use) }\end{array}$} & $\begin{array}{l}\text { Fuel (Gasoline + } \\
\text { Diesel) (I) }\end{array}$ & 810,000 & 1.5 million \\
\hline & & & $\mathrm{CO} 2$ (metric tons) & 2,000 & 3,700 \\
\hline & & & $\begin{array}{c}\text { No. of Vehicles taken } \\
\text { off the road }\end{array}$ & 800 & 1,500 \\
\hline
\end{tabular}

requirements. This is likely due to a combination of factors, including the usage patterns of these infrequently used vehicles might reduce profitability for the operators under the existing pricing schemes and business models by creating over demand during, e.g., weekends and holidays. However, considering that the mobility space is changing rapidly, we can see that there is a chance for a new service model to develop, either through expansion or through diversification of car sharing or other actors such as car dealers or car rental companies further joining the space. Combinations and collaborations between the different actors and development of new business models are additional ways forward.

If more actors in the mobility space were to shift toward a discourse highlighting the connection between vehicle attributes and their specific usage, there could be a move toward an unbundling of the vehicles. This would allow for a diversification of modes and hence a reduction of environmental impact. This could also benefit the diffusion and acceptance of electric vehicles as personal vehicles that work perfectly fine for daily use but where the limited range makes them less suitable for those infrequent longer trips.

One of the prerequisites for an "infrequent use" car-sharing service to work is a high variety of vehicle models in the car-sharing fleet, i.e., not only mid-size vehicles, but also larger vehicles such as 7-seaters, mini-vans and AWD. According to the literature and our interview results, for car-sharing companies to achieve such diversity they need to achieve a certain size and customer base. Thus supporting car sharing is an important step for enabling the possibility for it to provide "infrequent use" services.

One limitation of our study is that the consumer perspective is solely based on literature on vehicles or car sharing. There is a need to test the idea of unbundling the car into a "daily use" vehicle and an "infrequent use" service from a consumer perspective. Is it at all attractive for consumers? To validate this, there are a number of questions that should be addressed in future research. One area is to better understand what the "infrequent needs" are both when it comes to how often they actually occur, for how long they are used, and what attributes are needed. The attractiveness, design, and better understanding of the business model of an unbundling of the vehicle could be addressed through constructing choice experiments and stated preferences. Issues that would need to be studied are willingness to pay, convenience, distance to shared vehicle, and pricing schemes. This might also be useful to better understand what kind of services and vehicles the consumer would want and what combinations are most attractive-more research is needed on the consumers' attitude and experience relative to the framework presented here. There is also a need for more research on the connection between vehicle use and vehicle choice both related to conventional vehicles but also in the context of car-sharing research. This connection and the role of vehicle attributes related to choice could be incorporated in more user-based surveys and studies. 
Acknowledgments Area of Advance Transport at Chalmers and the Precourt Energy Efficiency Center are acknowledged for funding of the project. We would also like to thank all our interviewees for participating in the study.

\section{Compliance with ethical standards}

Conflict of interest The authors declare that they have no conflict of interest.

Open Access This article is distributed under the terms of the Creative Commons Attribution 4.0 International License (http:// creativecommons.org/licenses/by/4.0/), which permits unrestricted use, distribution, and reproduction in any medium, provided you give appropriate credit to the original author(s) and the source, provide a link to the Creative Commons license, and indicate if changes were made.

\section{References}

Abdel-Razzaq, L. (2011). Relay rides redesigns car sharing. Automotive News, 85(6463), 6.

Ballús-Armet, Ingrid, et al. (2014). Peer-to-peer (P2P) carsharing: exploring public perception and 1 market characteristics in the san francisco bay area 2, Transportation Research Board 93rd Annual Meeting.

Baptista, P., Melo, S., \& Rolim, C. (2014). Energy, environmental and mobility impacts of car-sharing systems. Empirical results from Lisbon, Portugal. Procedia - Social and Behavioral Sciences, 111(0), 28-37.

Bellos, I., Ferguson, M., \& Toktay, L. B. (2017). The car sharing economy: interaction of business model choice and product line design. Manufacturing \& Service Operations Management, 19(2), 185-201.

Bergstad, C. J., et al. (2010). Subjective well-being related to satisfaction with daily travel. Transportation, 38(1), 1-15.

Bert, Julien, et al. (2016). What's ahead for car sharing, The new mobility and its impact on vehicle sales, 1-17.

Björnsson, L.-H., \& Karlsson, S. (2015). Plug-in hybrid electric vehicles: how individual movement patterns affect battery requirements, the potential to replace conventional fuels, and economic viability. Applied Energy, 143, 336-347.

Bolduc, D., Boucher, N., \& Alvarez-Daziano, R. (2008). Hybrid choice modeling of new technologies for car choice in Canada. Transportation Research Record, 2082, 63-71.

Cairns, S (2011). Accessing cars: different ownership and use choices.

Cervero, Robert, Golub, Aaron, and Nee, Brendan (2007). City CarShare: longer-term travel demand and car ownership impacts, Transportation Research Record: Journal of the Transportation Research Board, 1992 (-1), 70-80.
Choo, S., \& Mokhtarian, P. L. (2004). What type of vehicle do people drive? The role of attitude and lifestyle in influencing vehicle type choice. Transportation Research Part A: Policy and Practice, 38(3), 201-222.

Clewlow, R. R. (2016). Carsharing and sustainable travel behavior: results from the San Francisco Bay Area. Transport Policy, 51, 158-164.

de Lorimier, A., \& El-Geneidy, A. M. (2013). Understanding the factors affecting vehicle usage and availability in Carsharing networks: a case study of Communauto Carsharing System from Montréal, Canada. International Journal of Sustainable Transportation, 7(1), 35-51.

Delbosc, A., \& Currie, G. (2013). Causes of youth licensing decline: a synthesis of evidence. Transport Reviews, 33(3), 271-290.

Dittmar, H. (1992). The social psychology of material possessions - to have is to be. Hertfordshire: Harvester Wheatsheaf.

Eppstein, M. J., et al. (2011). An agent-based model to study market penetration of plug-in hybrid electric vehicles. Energy Policy, 39(6), 3789-3802.

Ewing, G., \& Sarigöllü, E. (2000). Assessing consumer preferences for clean-fuel vehicles: a discrete choice experiment. Journal of Public Policy \& Marketing, 19(1), 106-118.

Firnkorn, J., \& Müller, M. (2011). What will be the environmental effects of new free-floating car-sharing systems? The case of car2go in Ulm. Ecological Economics, 70(8), 1519-1528.

Firnkorn, J., \& Müller, M. (2012). Selling mobility instead of cars: New business strategies of automakers and the impact on private vehicle holding. Business Strategy and the Environment, 21(4), 264-280.

Glotz-Richter, M. (2012). Car-Sharing-"car-on-call” for reclaiming street space. Procedia-Social and Behavioral Sciences, 48, 1454-1463.

Gonder J., Markel T., Simpson A., Thorton M. (2007). Using GPS travel data to assess the real world driving energy use of plugin hybrid electric vehicles (PHEVs), Transportation Reserach Board (Washington, D.C.).

Hampshire, Robert and Gaites, Craig (2011). Peer-to-peer carsharing, Transportation Research Record: Journal of the Transportation Research Board, 2217 (-1), 119-26.

Hawkins, T. R., et al. (2013). Comparative environmental life cycle assessment of conventional and electric vehicles. Journal of Industrial Ecology, 17(1), 53-64.

Heffner, R. R., Turrentine, T. S., \& Kurani, K. S. (2006). A primer on automobile semiotics. Davis, CA: Insitute of Transprotation studies.

Heffner, R. R., Kurani, K. S., \& Turrentine, T. S. (2007). Symbolism in California's early market for hybrid electric vehicles. Transportation Research Part D: Transport and Environment, 12(6), 396-413.

Hidrue, M. K., et al. (2011). Willingness to pay for electric vehicles and their attributes. Resource and Energy Economics, 33(3), 686-705.

Horne, M., Jaccard, M., \& Tiedemann, K. (2005). Improving behavioral realism in hybrid energy-economy models using discrete choice studies of personal transportation decisions. Energy Economics, 27(1), 59-77. 
Jakobsson, N., et al. (2016). Are multi-car households better suited for battery electric vehicles? - Driving patterns and economics in Sweden and Germany. Transportation Research Part C: Emerging Technologies, 65, 1-15.

Jorge, D., \& Correia, G. (2013). Carsharing systems demand estimation and defined operations: A literature review. EJTIR, 13(3), 201-220.

Khemani, R.S. and Shapiro, D.M. (1993), GLossary of Industrial Organisation Economics and Competition Law (OECD: directorate for financial, fiscal and enterprise affairs).

Kim, K. (2015). Can carsharing meet the mobility needs for the low-income neighborhoods? Lessons from carsharing usage patterns in New York City. Transportation Research Part A: Policy and Practice, 77, 249-260.

Koopman, Gert Jan (1995). Policies to reduce $\mathrm{CO}_{2}$ emissions from cars in Europe: a partial equilibrium analysis, Journal of Transport Economics and Policy, 53-70.

Kopp, J., Gerike, R., \& Axhausen, K. W. (2015). Do sharing people behave differently? An empirical evaluation of the distinctive mobility patterns of free-floating car-sharing members. Transportation, 42(3), 449-469.

Kuhnimhof, T., et al. (2012). Men shape a downward trend in car use among young adults - evidence from six industrialized countries. Transport Reviews, 32(6), 761-779.

Le Vine, S, Zolfaghari, A, and Polak, J (2014). Carsharing: evolution, challenges and opportunities, Brussels, 22nd European Automobile Manufacturers Association (ACEA) Scientific Advisory Group Report.

Loose, W., Mohr, M., \& Nobis, C. (2006). Assessment of the future development of car sharing in Germany and related opportunities. Transport Reviews, 26(3), 365-382.

Martin, E. W., \& Shaheen, S. A. (2011a). Greenhouse gas emission impacts of carsharing in North America. Intelligent Transportation Systems, IEEE Transactions on, 12(4), 1074-1086.

Martin, Elliot and Shaheen, Susan (2011b). The impact of carsharing on household vehicle ownership.

Martin, E., \& Shaheen, S. (2011c). The impact of carsharing on public transit and non-motorized travel: an exploration of North American carsharing survey data. Energies, 4(11), 2094-2114.

Martin, Elliot, Shaheen, Susan, and Lidicker, Jeffrey (2010). Impact of carsharing on household vehicle holdings, Transportation Research Record: Journal of the Transportation Research Board, 2143 (-1), 150-58.

Mau, P., et al. (2008). The 'neighbor effect': simulating dynamics in consumer preferences for new vehicle technologies. Ecological Economics, 68(1-2), 504-516.

Mishra, G. S., et al. (2015). The effect of carsharing on vehicle holdings and travel behavior: a propensity score and causal mediation analysis of the San Francisco Bay Area. Research in Transportation Economics, 52, 46-55.

momo, Car-sharing (2010). The state of European car-sharing, Final Report D 2.4 Work Package 2.

Musso, A., Corazza, M. V., \& Tozzi, M. (2012). Car sharing in Rome: a case study to support sustainable mobility. Procedia - Social and Behavioral Sciences, 48(0), 3482-3491.

Noppers, Ernst H., et al. (2014). The adoption of sustainable innovations: driven by symbolic and environmental motives, Global Environmental Change, (0).
Paundra, J., et al. (2017). Preferences for car sharing services: effects of instrumental attributes and psychological ownership. Journal of Environmental Psychology, 53, 121-130.

Pearre, N. S., et al. (2011). Electric vehicles: how much range is required for a day's driving? Transportation Research Part C: Emerging Technologies, 19(6), 1171-1184.

Prettenthaler, F. E., \& Steininger, K. W. (1999). From ownership to service use lifestyle: the potential of car sharing. Ecological Economics, 28(3), 443-453.

Prieto, M., Baltas, G., \& Stan, V. (2017). Car sharing adoption intention in urban areas: what are the key sociodemographic drivers? Transportation Research Part A: Policy and Practice, 101, 218-227.

Rabbitt, Niamh and Ghosh, Bidisha (2013), A study of feasibility and potential benefits of organised car sharing in Ireland, Transportation Research Part D: Transport and Environment, 25 (0), 49-58.

Schuitema, G., et al. (2013). The role of instrumental, hedonic and symbolic attributes in the intention to adopt electric vehicles. Transportation Research Part A: Policy and Practice, 48(0), 39-49.

SDOT (2014). 2013 Seattle free-floating car share pilot program report, (Seattle Department of Transportation).

Services, Office of the Mayor - Economic Growth (2011). Report to the city council: city of San Diego's all-electric vehicle carshare pilot program.

SFMTA (2013). Car sharing policy and pilot project, (San Francisco Municipal Transportation Agency).

Shaheen, Susan and Cohen, Adam (2014). Innovative mobility carsharing outlook, (3).

Shaheen, S., \& Cohen, A. P. (2013). Carsharing and personal vehicle services: worldwide market developments and emerging trends. International Journal of Sustainable Transportation, 7(1), 5-34.

Shaheen, Susan A., Mallery, Mark A., and Kingsley, Karla J. (2012), Personal vehicle sharing services in North America, Research in Transportation Business \& Management, 3 (0), 71-81.

Sinha, S. (2011). A simulation study of peer-to-peer carsharing. IEEE Forum on Integrated and Sustainable Transportation Systems, 2011, 159-163.

Skippon, S., \& Garwood, M. (2011). Responses to battery electric vehicles: UK consumer attitudes and attributions of symbolic meaning following direct experience to reduce psychological distance. Transportation Research Part D: Transport and Environment, 16(7), 525-531.

Sochor, J. L., Strömberg, H., \& Karlsson, M. A. (2015). Implementing mobility as a service: challenges in integrating user, commercial, and societal perspectives. Transportation Research Record, 4(2536).

Sprei, F., \& Wickelgren, M. (2011). Requirements for change in new car buying practices-observations from Sweden. Energy Efficiency, 4(2), 193-207.

Sprei, F., \& Karlsson, S. (2013). Energy efficiency versus gains in consumer amenities - an example from new cars sold in Sweden. Energy Policy, 53, 490-499.

Sprei, Frances and Ginnebaugh, Diana (2015). Can car sharing facilitate a more sustainable car purchase?, ECEEE Summer Study (Toulon/Hyeres, France).

Statistics Sweden (2015). Fordonsstatistik, <http://www.scb. se/hitta-statistik/statistik-efter-amne/transporter-och- 
kommunikationer/vagtrafik/fordonsstatistik/>, accessed 2015-12-05.

Steg, L. (2005). Car use: lust and must. Instrumental, symbolic and affective motives for car use. Transportation Research Part A: Policy and Practice, 39(2-3), 147-162.

Sullivan, J.L., Salmeen, I.T., and Simon, C.P. (2009). PHEV marketplace penetration: an agent based simulation., University of Michigan Transportation Research Insitute Report, UMTRI-2009-32.

Sullivan, John L., et al. (1998),Life cycle inventory of a generic U.S. family Sedan overview of results USCAR AMP Project, (SAE International).
Trafikverket (2012). Utvärdering av effektsamband för bilpool, (Trafikverket - Swedish Road Agency).

Trafikverket (2013). Vägen framåt för svenska bilpooler, (Trafikverket - Swedish Road Agency).

Turrentine, T. S., \& Kurani, K. S. (2007). Car buyers and fuel economy? Energy Policy, 35(2), 1213-1223.

USDOT. (2015). Highway. Statistics, 2013.

Veblen, T. (1899). The theory of the leisure class. New York: Penguin. 